\title{
Metastatic Malignant Neoplasm in the Rectum
}

National Cancer Institute

\section{Source}

National Cancer Institute. Metastatic Malignant Neoplasm in the Rectum. NCI

Thesaurus. Code C7426.

The spread of a malignant neoplasm to the rectum. This may be from a primary large intestine malignant neoplasm, or from a malignant neoplasm at a distant site. 